\title{
Correction to: "A Temple of God": A Qualitative Analysis of the connection Between Spiritual/Religious Beliefs and Health Among Mormons
}

\section{Bárbara Badanta ${ }^{1,2}$ (D) $\cdot$ Giancarlo Lucchetti ${ }^{3}$ (D) $\cdot$ Rocío de Diego-Cordero $^{1,4}$ (D)}

Published online: 5 November 2019

(c) Springer Science+Business Media, LLC, part of Springer Nature 2019

\section{Correction to: Journal of Religion and Health https://doi.org/10.1007/s10943-019-00922-7}

The original version of the article was inadvertently published with textual error. The word "first author" should be corrected as "last author" in the fifth paragraph of Sample section. The corrected text is given below:

"The last author of this article has experience in this topic and has previously developed an ethnographic research with the SUD community in Spain for more than 2 years in order to know the social behaviour of this movement".

The original article has been corrected.

Publisher's Note Springer Nature remains neutral with regard to jurisdictional claims in published maps and institutional affiliations.

The original article can be found online at https://doi.org/10.1007/s10943-019-00922-7.

Rocío de Diego-Cordero

rdediego2@us.es

Bárbara Badanta

bbadanta@us.es

https://cespyd.es/en/

Giancarlo Lucchetti

g.lucchetti@yahoo.com.br

1 Faculty of Nursing, Physiotherapy, and Podiatry, University of Seville, C/Avenzoar, 6, 41009 Seville, Spain

2 Research Group: Coalition for the Study of Health, Power, and Diversity, Center of Community Research and Action at the University of Seville, Seville, Spain

3 Department of Medicine, School of Medicine, Federal University of Juiz de Fora, Juiz de Fora, Brazil

4 Research Group CTS 969 "Innovation in HealthCare and Social Determinants of Health", School of Nursing, Physiotherapy and Podiatry, University of Seville, Seville, Spain 